\title{
Improvement of Human Resource Management in the Quality Management System of the Enterprise
}

\author{
Tatyana Mozhaeva ${ }^{1, *}$ \\ ${ }^{1}$ Bryansk State Technical University, 7, 50 years of October st., Bryansk, 241035, Russia
}

\begin{abstract}
The paper deals with the principles of improving the management of human resources in the quality management system (QMS) of the enterprise, based on the concept of human resources management and process approach in accordance with the requirements of international standards ISO 9000:2015. There is a dual nature of human resources identified, where the staff is considered, on the one hand, as the most important, specific resource determining the competitiveness of the enterprise, and, on the other hand, as an internal consumer of the rewarding mechanism offered to employees for quality work. The procedure to design personnel processes of QMS of the enterprise is considered. The expediency of integrating IDEF0 model and the methodology of functional cost analysis (FCA) into the enterprise's QMS. There is no formal approach to analysis and assessment of personnel risks in the management of processes. The application of SWOT analysis adapted to the personnel management of the enterprise is justified in order to use it for controlling QMS personnel risks. There are criteria given to apply this approach to ensure the quality of personnel processes in QMS of the enterprise.
\end{abstract}

\section{Introduction}

Nowadays the effective functioning of the quality management system (QMS) of an enterprise should include ensuring the quality of its process management as well. In accordance with the new version of ISO 9000:2015 enterprises that have implemented and developed their QMS should define, evaluate and improve the processes necessary for its effective operating, in particular personnel processes. At the same time, human resources are given special significance compared to the rest of the enterprise's resources.

The availability of a large range of tools and technologies to design correct QMS personnel processes demonstrates the continuing interest of researchers and experts to this issue. However, the majority of enterprises having implemented QMS have not received the expected results, including in improving product quality. This fact is explained, in particular, by the formal approach to human resources that do not take into account their specificity, and by insufficient development of personnel processes, which does not allow to control them effectively. In this regard, there is a need to rethink the methodological approaches to human resource management in the enterprise's QMS.

\footnotetext{
* Corresponding author: goa-bgtu@mail.ru
} 


\section{Analysis of scientific researches and papers}

Analysis of scientific references in this subject area has allowed us to come to the conclusion that, personnel processes are characterized by the following, in particular [1-5]:

- the absence in the scientific community of an unambiguous understanding of human resources nature (the personnel is considered as a resource, valuable asset, product), which complicates the work on structuring and describing personnel processes;

- the substitution of the essence of the process with a functional approach to the development and management of personnel activities, which leads to ambiguity in determining the object, level, results, etc. of this management activity;

- limited practical use of tools to justify the optimal structure of personnel processes, balancing the significance of the processes in the management structure and the costs of their implementation;

- development of personnel risk management mainly in the context of eliminating threats resulted from personnel activities, which does not allow the organization to make maximum use of opportunities created by human resources;

- the lack of models to manage personnel risk and opportunities, which reduces the reliability of the research results;

- describing indicators of results and efficiency of personnel processes through the formal characteristics of human resources and the lack of their relationship with the quality of labor and products.

According to the analysis of publications, the improvement of personnel processes in the QMS is relevant, as it allows to reduce the level of uncertainty in personnel management, to improve the quality of work and employee satisfaction.

\section{Problem statement}

To eliminate the identified shortcomings and to improve personnel management, it is necessary to:

- identify the human resources of the enterprise in the context of a process-based approach;

- to adjust the model of QMS personnel processes taking into account the peculiarity of human resources and the basic conceptual requirements of ISO 9000:2015;

- to develop a procedure for monitoring QMS risks.

In this connection, studies aimed at concretizing the nature of human resources and developing a personnel process model are of particular importance.

\section{The nature of human resources in the context of process approach}

Effective and efficient management of human resources of an enterprise is impossible without a clear identification of the object of management. Since there are disputes in the scientific community on the nature of human resources it indicates the absence of unity of views on the object of management.

On the basis of the concept of human resource management in personnel management, they determine the area of activity related to managing people to achieve the strategic goals of an enterprise, and types of activities within the established boundaries - functions, a priori accepting a single management object (resource, product, asset, etc. [1-5]). However, practice shows that if we consider human resource management from the standpoint of the process approach, which has more detailed parameters of personnel activities, it becomes 
obvious that the object of management (like the personnel processes themselves) is heterogeneous. Combined into one functional structure, processes have different suppliers and consumers. If for the majority of personnel processes the consumer is the enterprise, and the supplier is the personnel, then for motivational processes, on the contrary, the consumer is the personnel, and the supplier is the enterprise.

In this regard, it seems appropriate to define the nature of human resources as dual, where the personnel is considered, on the one hand, as the most important, specific resource that determines the competitiveness of the enterprise, and, on the other hand, as an internal consumer of the rewarding mechanism (wages and benefits, promotion, training programs, the importance of work, etc.) offered to employees for quality work [6].

At the same time, the object of managing personnel processes is also dual:

- a specific resource that needs to be managed like any other enterprise resource;

- a rewarding system that an enterprise can offer an employee as an internal consumer.

The proposed approach to the management of human resources of the enterprise, taking into account their dual nature, will ensure the correct development of personnel processes in QMS.

\section{The model of human resources management in QMS}

The model of human resources management of the enterprise's QMS is based on the process approach and the dual nature of human resources. A new version of ISO 9001 : 2015 defines the process approach as planning of organization processes and their interaction; implementing PDCA cycle and risk-based thinking, allowing to determine the factors that may cause deviation from the planned results of processes and QMS of the organization, and also to use preventive actions to minimize negative consequences and maximize the use of opportunities.

According to the interpretation of the process approach by the standard ISO 9001:2015, the model of human resource management provides for the implementation of the following actions:

- development of a typical registry of processes that take into account the dual nature of human resources;

- design of personnel processes based on the integration of IDEF0 methodology and functional cost analysis (FCA);

- optimization of personnel processes, providing for the harmonization of the significance of the process in the overall structure of personnel processes and the costs of its implementation;

- identifying the indicators of the efficiency of personnel processes.

The process model "Human Resource Management" provides for a clear decomposition of QMS personnel subsystem into integrated processes, in particular: "Human Resource Management", whose consumer is the enterprise; "Management of the Motivation System", whose consumer is the supplier; "Harmonization of Personal and Organizational Requirements", allowing to manage the balance of employee and company's interests; "Personnel Provision of Work Quality", which allows to link performance indicators, showing the satisfaction of the enterprise with the resource and expressed in the personnel competence, with ensuring the level of quality and productivity of labor and the satisfaction of the personnel with the reward system offered by the enterprise.

Taking into account the identified peculiarities of the personnel management, a typical register of processes "Enterprise Human Resource Management" has been developed (Table 1) [6]. The proposed registry based on the integration of personnel processes and the dual nature of human resources allows: 
Table 1. Process Registry "Enterprise Human Resource Management".

\begin{tabular}{|c|c|}
\hline 1. & Human resource management \\
\hline 1.1. & Development of human resource management policy and strategy \\
\hline 1.1.1. & Development of personnel policy \\
\hline 1.1.1.1. & Definition of organization values \\
\hline 1.1.1.2. & Forming organization behavior model \\
\hline 1.1.2. & Development of human resource strategy of the enterprise \\
\hline 1.1.2.1. & Analysis of the labor market and personnel potential of the enterprise \\
\hline 1.1.2.2. & Cost planning of human resources \\
\hline 1.1.2.3. & Human resource requirement planning \\
\hline 1.2. & Recruiting \\
\hline 1.2.1. & Recruitment \\
\hline 1.2.2. & Personnel selection \\
\hline 1.2 .3 . & Personnel hiring and displacement \\
\hline 1.3. & Personnel adaptation and career guidance \\
\hline 1.3.1. & Personnel adaptation \\
\hline 1.3.2. & Personnel career guidance \\
\hline 1.4. & Personnel development \\
\hline 1.4.1. & Personnel training \\
\hline 1.4.2. & Personnel career planning \\
\hline 1.5. & Personnel management \\
\hline 1.5 .1 & Facilitating the formation of organization departments \\
\hline 1.5.2. & The definition of salaries and benefits \\
\hline 1.5 .3 . & Management of recording activities \\
\hline 1.5.4. & Consulting line managers \\
\hline 2. & Motivational system management \\
\hline 2.1. & Identification of personal values \\
\hline 2.2. & Development of motivational programs \\
\hline 2.2 .1 . & Designing the pay system and tangible assets \\
\hline 2.2 .2 . & Designing the training system \\
\hline 2.2 .3 & Designing the system of promotion \\
\hline 2.2 .4 & Designing labor conditions and work importance \\
\hline 2.2 .5 . & Documentation of motivational programs \\
\hline 2.3. & Personnel Motivating \\
\hline 2.3.1. & Implementation of motivational programs \\
\hline 2.3.2. & Motivational programs monitoring \\
\hline 3. & Harmonization of personal and organizational requirements \\
\hline 3.1. & Analysis of enterprise personnel satisfaction (certification) \\
\hline 3.2. & Analysis of employee satisfaction with the enterprise \\
\hline 3.3. & Harmonization of personal and organizational values \\
\hline 4. & Human resources for quality and productivity \\
\hline 4.1. & Identification of performance and labour quality parameters \\
\hline 4.2. & Personnel management of productivity and quality \\
\hline 4.3. & Evaluation of performance and labour quality indicators \\
\hline
\end{tabular}

- to eliminate the existing shortcomings in personnel management - the lack of a clear separation of operational and strategic human resource processes in QMS of the organization; processes mixing with different customers (enterprise and personnel) and 
management objects (human resource and rewarding systems) that leads to discrepancy of final scheduled performance indicators of the process content;

- to harmonize the interests and expectations of the employer and the employees, thereby maximizing the potential of human resources in the organization that will enhance the efficiency of its QMS.

Ensuring the quality of personnel processes involves their correct design as well [7-10]. The design of processes is based on the assumption that the set of processes defines a certain structure within which the functions are implemented. The function acts as the object essence, and the process - as its manifestation form. Developing, the structure undergoes qualitative and quantitative changes. If the structure does not correspond to the functions, then it must be corrected, optimized.

The identification of tools and technologies that enables to design the enterprise's QMS processes is undoubtedly of scientific and practical interest. To solve this problem, it is promising to integrate IDEF0 methodology and functional cost analysis (FCA) for rational structuring and justifying the costs of personnel processes (Fig. 1).

\section{$\underline{\text { IDEF0 }}$}

\section{$\underline{\text { FCA }}$}

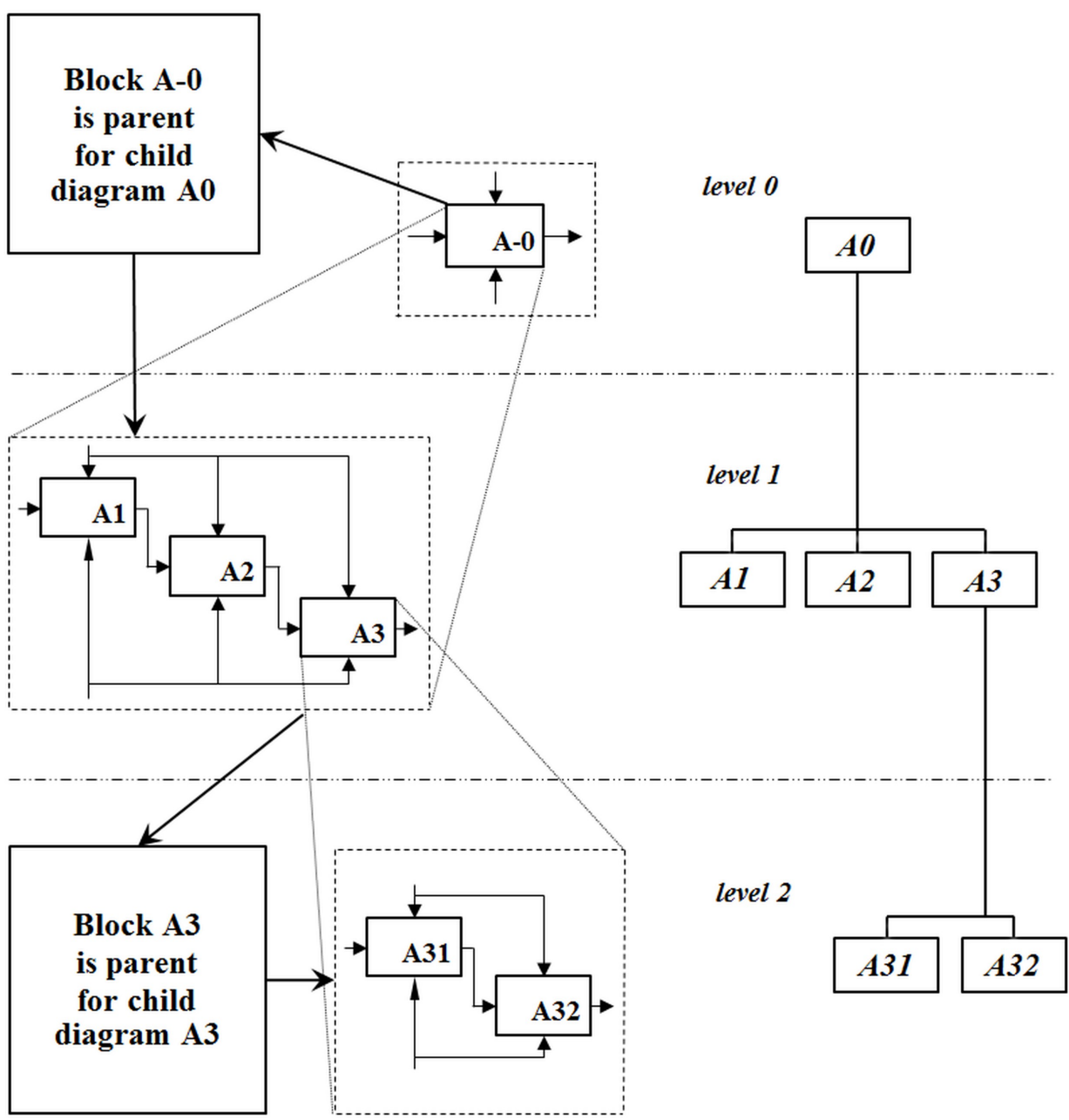


Fig. 1. An example of the decomposition of functional diagram A - 0 based on IDEF0 methodology and its functional model based on FCA.

IDEF0 is used to create a functional model that displays the structure and functions of the personnel system at all its levels, as well as the flows of information and material objects in it. Correctly structured processes allow, in particular:

- to visualize personnel activities in the form of a model of processes that reflect the ideal interconnection and interdependence of processes from the point of view of the enterprise's top management;

- to reduce the level of uncertainty of the enterprise personnel about the place and role of the processes performed by them in increasing the value of products (services);

- to identify indicators that allow the organization's staff, managers and all concerned parties to evaluate objectively the efficiency of processes.

The task to optimize processes by identifying and eliminating duplicate or ineffective functions, minimizing the cost of their implementation is solved by the functional cost analysis [11-15]. The removal of elements from the object (process) under the study that do not carry the proper functional load is the fundamental principle which is helpful to improve QMS personnel processes in FCA methodology.

Application of FCA methodology to human resource management in QMS should take into account personnel features, in particular:

- the complexity of structuring personnel processes, caused by the practical absence of unification and rationing of these types of work;

- unacceptability of minimizing costs to personnel processes, due to the peculiarity of this activity, including its social significance, which requires an approach to the processes from the standpoint of optimal costs and adaptation of FCA methodology to them;

- the analysis efforts, which require to develop appropriate software and tools to automate the process of managing personnel costs.

The construction of a functional model of personnel processes based on FCA is carried out in tabular form or in the form of a hierarchical diagram depicting the grouped functions of the object under study in the form of levels (tiers) arranged from left to right or from top to bottom (Fig. 1). Conducting FCA in relation to QMS personnel processes can be represented by the following algorithm $[12,13]$ :

1. Formulation of the process functions under study and their classification taking into account structuring on the basis of IDEF0, in particular:

- the main function (context diagram A - 0) - determines the purpose of the process as a whole;

- the key function (functional diagram A0) - creates the necessary conditions for the implementation of the main function;

- the auxiliary function (derived diagrams of functional diagram A1, ..,n) - contributes to the implementation of key functions.

2. Determination of function significance - the weight of function groups that are on the same level of a functional model, and the relative importance of functions - the weight of functions (level weight) regarding to the analysis as a whole.

3. Determination of costs for performing functions, in absolute and relative terms. Costs can be calculated on the basis of methods known in management practice.

4. Comparison of quantitative estimates of functions with the cost of their execution in order to identify inconsistencies (disbalance zones), i.e. exceeding the cost for functions over their significance in the structure of the object (process) as a whole.

5. Identification and elimination of the causes of discrepancy between significance (importance), quality and costs. FCA methodology allows us to establish where cause-andeffect relations of processes are not correctly formed, which creates prerequisites for their improvement. 
According to the proposed approach, indicators of personnel processes efficiency are formed, which should be focused on the integrated achievement of the employer and the employee's interests. In this regard, it is advisable to consider the integral indicator - the quality of work - as an indicator of personnel processes efficiency. At the same time, the consideration stated in GOST $15467-79$ is preferable, where the quality of work is described as a complex of work activity features, determined by the ability and desire of the employee to perform the task in accordance with the established requirements. From which it follows that the quality of work depends on the content of labor, the competence of the employee and his attitude to work. Within the personnel process, a fairly extensive system of work quality indicators is built, which can be managed on the basis of the hierarchy analysis method [10]. The method allows to establish a hierarchy of goals, factors and alternatives to improve the quality of work, as well as to prioritize the elements of each level in the hierarchy.

Designing processes based on the integration of IDEF0 methodology and functional cost analysis contributes to their efficiency of enterprise's QMS.

\section{Management of human risk in QMS}

Managing QMS processes, including personnel processes, in the context of ISO 9001:2015 standards involves applying a risk-based approach to them, which allows to identify factors that may lead to deviations from planned results, as well as to use preventive management actions to minimize negative consequences and maximize arising opportunities. It should be noticed that human resources have the highest degree of uncertainty compared with other resources of the organization, since only staff is able to influence control actions by changing them $[11,16]$. This requires to use personnel risk management tools taking into account their peculiarities.

The risk assessment tools proposed in human resource management are not widely represented (human resource administration (HRA), hazard analysis and critical control point (HACCP), etc.) and are focused only on identifying errors made by the staff. There are no methods for assessing opportunities related to human factors.

Perspective from the point of view of identifying both risks and opportunities created by personnel processes is SWOT - analysis recommended by ISO 31000: 2018, ISO / IEC 31010: 2009 and adapted for use in personnel management. This tool originally has an approach to take into account risks and possibilities of internal and external environment factors influencing the organization development, which makes it possible to use SWOT analysis as a completely independent model for analyzing, evaluating and choosing a strategy for managing risks and operating capabilities of an organization's QMS. The method to evaluate personnel risks based on SWOT - analysis and statistical justification of the results obtained is presented in Fig. 2 [17].

The traditional method of conducting SWOT - analysis is not without a number of shortcomings associated with the lack of statistical justification for the results obtained, in particular in the field of $[18,19]$ :

- assessment and selection of causal external and internal factors of influence on the enterprise (in the context of the risks and opportunities they create) for forming development strategies, and therefore the reliability of the results of analyzing selected factors is reduced or an unnecessarily large array of selected factors is formed, which, given the limited resources of the enterprise, cannot be quickly implemented and distracts it from solving priority tasks;

- identifying strategies to minimize hazards or use development opportunities, which are not able to provide a quantitative measurement of forecast options and alternative actions. 
As practice shows, in a situation where a risk-based approach to managing QMS processes, including personnel processes, is considered as a condition and a conscious need for their effective functioning, the proposed procedure for statistical justification of SWOT analysis results is relevant and allows to avoid identified shortcomings.

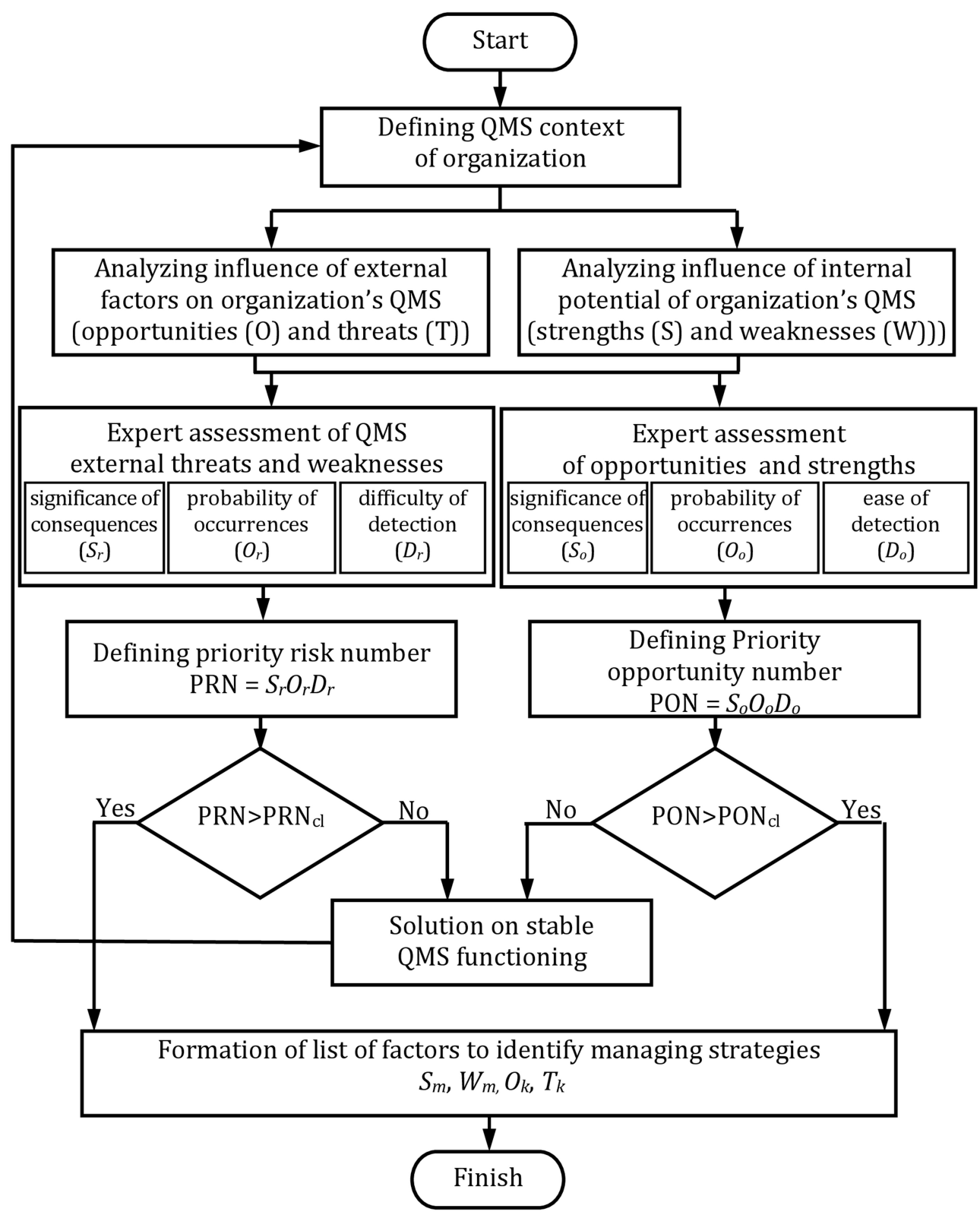

Fig. 2. Algorithm for evaluating personnel risks based on SWOT - analysis.

\section{Conclusion}

The analysis of designing and improving QMS processes, in particular, personnel processes, demonstrated the ambiguity of this management phenomenon. Scientific 
discussions for determining the management object (the nature of human resources), limited practical use of tools to justify the optimal structuring of personnel processes, the balance of processes significance in the management structure and the cost of their implementation, the lack of tools to identify opportunities offered to the company through human potential, weak methods for assessing personnel risks and identification of management strategies of these processes reducing the reliability of the results obtained make necessary to develop methods to avoid the identified disadvantages.

The proposed approach to improving human resource management processes of QMS, based on the dual nature of human resources and designing personnel processes focused on the integration of tools such as IDEF0 methodology, functional cost analysis, SWOT analysis, will not only ensure the quality of the considered processes, but also enterprise products in general.

\section{References}

1. J. Storey, New Perspectives on Human Resource Management (Routledge Revivals, London, 2014)

2. K. Jiang, D.P. Lepak, K. Han, Y. Hong, A. Kim, A.L. Winkler, Human Resource Management Review, 22, 73 (2012)

3. D. Guest, Human Resource Management Journal, 9, 5 (1999)

4. P.F. Buller, G.M. McEvoy, Human Resource Management Review, 22, 43 (2012)

5. B.A. Campbell, R. Coff, D. Kryscynski, Academy of Management Review 37, 95 (2012)

6. T.P. Mozhaeva, Quality. Innovations. Education, 7, 52 (2014)

7. T. Aized, Total Quality Management And Six Sigma (InTech, Rijeka, 2016)

8. J. Łuczak, Economics, entrepreneurship, management, 2, 33 (2015)

9. L.Z. Miletic, A.D. Jovanovic, F.P. Jovanovic, Vojnotehnicki Glasnik: Military Technical Courier, 65, 731 (2017)

10. T.L. Saaty, The Analytic Hierarchy Process (McGraw-Hill, New York, 1980)

11. S. Micleaa, A. Pugnaa, R. Negreaa, S. Potraa, Procedia - Social and Behavioral Sciences, 238, 133 (2018)

12. T. Yoshikawa, J. Innes, F. Mitchell, International Journal of Production Economics, 36, 53 (1994)

13. T. Yoshikawa, J. Innes, F. Mitchell, Management Accounting Research, 6, 415 (1995)

14. F. Chichernea, R. Silhavy, R. Senkerik, Z. Oplatkova， Z. Prokopova， P. Silhavy, Software Engineering in Intelligent Systems. Advances in Intelligent Systems and Computing, 349, 359 (2015)

15. A.Y.S. Duarte, M.C. Favaro, F.M. Santiciolli, F.G. De, Global Journal of Research In Engineering, 15, 1 (2015)

16. R. Deneckere, A. Palma, L. Leruth, International Journal of Industrial Organization, 65, 173 (2019)

17. O.A. Gorlenko, T.P. Mozhaeva, Science vector of Togliatti State University, 1, 13 (2018) 
18. G. Houben, K. Lenie, K. Vanhoof, Decision Support Systems, 26, 125 (1999)

19. G. Panagiotou, Business Strategy Review, 14, 8 (2003) 